\title{
Gastroprotective effect of mucilage fraction from Solenostemma argel via cytoprotection and attenuation of oxidative stress, inflammation and apoptosis
}

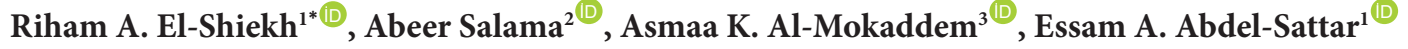 \\ ${ }^{1}$ Department of Pharmacognosy, Faculty of Pharmacy, Cairo University, Kasr el Aini st., Cairo 11562, Egypt \\ ${ }^{2}$ Department of Pharmacology, Medical Division, National Research Centre, El-Bouhouth St., Cairo, 12622, Egypt \\ ${ }^{3}$ Department of Pathology, Faculty of Veterinary Medicine, Cairo University, Giza Square, Giza 12211, Egypt
}

\section{A R T I C L E I N F O}

Article Type:

Original Article

Article History:

Received: 8 July 2020

Accepted: 27 August 2020

\section{Keywords:}

Gastric ulcer

Mucilage

Cytoprotection

Cell proliferation

Apoptosis

Oxidative stress

\begin{abstract}
A B S T RA C T
Introduction: Polysaccharides have numerous therapeutic values including immunity stimulation, angiotensin converting enzyme inhibition, wound healing, anti-diabetic and cytotoxic activities, in addition to their potent anti-oxidant properties. This work examined the gastroprotective and ulcer healing potential of mucilage fraction isolated from Solenostemma argel (Delile) Hayne (MFA) against ethanol-induced gastric ulcer in rats.

Methods: Forty Sprague-Dawley rats were divided into five groups $(\mathrm{n}=8)$; normal control (I), ethanol control (II), $20 \mathrm{mg} / \mathrm{kg}$ Antodine pretreated rats (III), $100 \mathrm{mg} / \mathrm{kg}$, and $200 \mathrm{mg} / \mathrm{kg}$ MFA pretreated rats, respectively (IV \& V). All rats in groups II-V received single intragastric dose of ethanol $(5 \mathrm{~mL} / \mathrm{kg})$ to induce gastric ulcer. Gastric mucosal injuries were assessed by stomach gross examination as well as histopathology, and immunohistochemistry of apoptotic markers. Also, several biochemical parameters including oxidative stress, proinflammatory cytokines, cytoprotective and cell proliferative biomarkers were measured.

Results: High-performance liquid chromatography (HPLC) analysis of MFA revealed its composition of glucose, $\mathrm{D}$-fucose and $\mathrm{N}$-acetyl glucosamine as monosaccharaides, in addition to glucuronic and galacturonic acids. The data showed that MFA, $200 \mathrm{mg} / \mathrm{kg}$ had potent antioxidant, anti-inflammatory, cytoprotective, cell proliferative, and antiapoptotic activities which were better than Antodine.

Conclusion: This study revealed that MFA had significant gastroprotective effects against ethanol-induced gastric injuries and could be a promising adjuvant therapy for ulcer treatment.
\end{abstract}

Implication for health policy/practice/research/medical education:

Mucilage fraction of Solenostemma argel (Delile) Hayne exhibited potent anti-oxidant, anti-inflammatory, cytoprotective, cell proliferative, and antiapoptotic activities, which may have significant implications for the future development of anti-ulcer drugs derived from Argel.

Please cite this paper as: El-Shiekh RA, Salama A, Al-Mokaddem AK, Abdel-Sattar AE. Gastroprotective effect of mucilage fraction from Solenostemma argel via cytoprotection and attenuation of oxidative stress, inflammation and apoptosis. J Herbmed Pharmacol. 2021;10(2):232-240. doi: 10.34172/jhp.2021.26.

\section{Introduction}

Plant mucilage as a chemical class of polysaccharides has obtained abundant interest nowadays due to their numerous applications in pharmacy (1), as well in pharmaceutical and food industries (2). They could be used for treatment of musculoskeletal, urinary, respiratory, gastrointestinal, immunomodulation, and skin disorders through oral or topical forms (3). Mucilage compounds are also used in pharmaceutical industries as disintegrating, binding, gelling, and suspending agents or emulsion stabilizers (4).

Solenostemma argel (Delile) Hayne (Asclepiadaceae) is an Egyptian wild perennial dessert shrub, used in traditional medicine as an antispasmodic, antiinflammatory, and anti-rheumatic herb. It showed also hypoglycemic, hypolipidemic and weight loss activities in 
experimental animals (5).

Gastric ulcer is a very common public health condition worldwide $(6,7)$. It is provoked by an imbalance between destructive and defensive factors in the stomach (8). The Helicobacter pylori infection, psychological stress, unhealthy dietary habits, ethanol consumption and the prolonged use of non-steroidal anti-inflammatory drugs are some factors, which can prompt the progress of gastric ulcers $(9,10)$. Natural products are becoming nowadays more attractive targets than the available synthetic drugs for ulcer treatment due to their availability, perceived effectiveness and lower cost with fewer side effects (11). In this study, we examined the gastroprotective effects of mucilage fraction from Argel (MFA) with the elucidation of the mechanism of action involved in these effects, to find more safe and effective therapy instead of synthetic ones.

\section{Materials and Methods}

Plant material

The aerial parts of $S$. argel (Delile) Hayne were collected from Aswan, Egypt in 2019 and dried in shade at room temperature. The plant was authenticated by Mrs Therese Labib, the Botanical specialist and consultant at Orman and Qubba Botanical Gardens. A voucher specimen (No. 30.11.2019) was placed in the Herbarium of the Department of Pharmacognosy, College of Pharmacy, Cairo University, Egypt.

\section{Preparation of MFA}

The powdered plant material (500 g) was mixed with $3 \mathrm{~L}$ of hot distilled water using ultrasonic (20 minutes) and left overnight. Then, the mucilage was prepared using the method as described by Radwan et al (12) and kept in vacuum desiccator over anhydrous calcium chloride to give $10 \mathrm{~g}$ of dried MFA.

\section{Chemical analysis of MFA}

\section{Acid hydrolysis of MFA}

MFA was hydrolysed according to a method described by Njintang et al (13). Briefly, $10 \mathrm{mg}$ of dried MFA was hydrolysed in $0.5 \mathrm{~mL} 2 \mathrm{M}$ trifluoroacetic acid for 2 hours at $80^{\circ} \mathrm{C}$. The acid hydrolysate was analysed by HPLC. Monosaccharides were expressed as g.100 g-1 carbohydrates.

HPLC condition for analysis of monosaccharaides Agilent1260 infinity HPLC Series (Agilent, USA), equipped with Quaternary pump, Phenomenex ${ }^{\circledR}$ Rezex RCM-Monosaccharide column $(300 \mathrm{~mm} \times 7.8 \mathrm{~mm}, 5 \mu \mathrm{m})$ run at $80^{\circ} \mathrm{C}$ and $\mathrm{RI}$ detector run at $40^{\circ} \mathrm{C}$. The separation was achieved using isocratic elution by HPLC grade water with $0.6 \mathrm{~mL} / \mathrm{min}$ as flow rate and $20 \mu \mathrm{L}$ injected volume.

HPLC condition for analysis of uronic acids HPLC (Knauer, Germany) condition was as follows: UV detector set at $214 \mathrm{~nm}$, Rezex $^{@}$ column $(300 \mathrm{~mm} \times 7.8$ $\mathrm{mm}, 5 \mu \mathrm{m}), 0.6 \mathrm{~mL} / \mathrm{min}$ flow rate, and oven temperature kept constant at $65^{\circ} \mathrm{C}$. The mobile phase was $0.005 \mathrm{M}$ $\mathrm{H}_{2} \mathrm{SO}_{4}$ data integration by ClarityChrom software.

\section{Biological assay}

Animals and chemicals

Sprague-Dawley male rats of 140-150 g were provided by the Animal House of the National Research Centre (Cairo, Egypt), grouped and housed under temperature and lightcontrolled conditions. All adopted procedures were in accordance with the guidelines of the EU Directive 1986; 2010/63/EU for animal experiments and were approved by the Institutional Research Ethics Committee at the Faculty of Pharmacy, Cairo University, Egypt (MP-2575).

Antodine ${ }^{\circledR}$ tablets were obtained from Amoun Pharmaceutical Industries, Cairo, Egypt. Reduced glutathione (GSH) and malondialdehyde (MDA) were procured from Biodiagnostic, Egypt. Interleukin-6 (IL6), myeloperoxidase (MPO), and tumor necrosis factoralpha (TNF- $\alpha$ ) were procured from Sinogeneclon Biotech Co., Ltd. Prostaglandin E2 (PGE2) was purchased from Elabscience Biotechnology Inc. Heat shock protein-70 (HSP-70) and vascular endothelial growth factor (VEGF) were purchased from NOVA, Beijing and Sunlong Biotech Co., Ltd, China.

\section{Gastric ulcer induction}

Animals were randomly assorted into five groups with each group containing eight rats. Group I (control group): normal rats which received saline vehicle $(5 \mathrm{~mL} / \mathrm{kg})$. Group II: (ethanol group): received a single intragastric dose of absolute ethanol $(5 \mathrm{~mL} / \mathrm{kg})$ to induce gastric ulcer (14). Group III: received a single intragastric dose of ethanol+ Antodine (20 mg/kg) (15). Group IV: received a single intragastric dose of ethanol+ MFA (100 mg/kg). Group V: received a single intragastric dose of ethanol+ MFA $(200 \mathrm{mg} / \mathrm{kg})$. The rats were given treatments and Antodine 1 hour before ulcer induction by oral gavage. The animals were euthanized under deep anesthesia. Following immediate laparotomy, stomachs were excised, opened along the greater curvature and rinsed with normal saline.

Gastric ulcer index (UI) and protection percentage An observer examined the gastric mucosal lesions expressed as ulcer index (UI) as previously described by Salama et al (16). The percentage of protection was calculated by the following formula: [(UI ethanol control-UI treated)/UI ethanol control] $\times 100$.

\section{Preparation of tissue homogenate}

The stomach was excised, washed with saline and placed in ice-cold phosphate buffer ( $\mathrm{pH} 7.4$ ) to prepare the $20 \%$ homogenate using a tissue homogenizer (MPW-120, BitLab Medical instruments, Poland). The supernatant was 
collected and stored at $-80^{\circ} \mathrm{C}$ and then used for estimation of biochemical parameters.

Histopathological examination

For histopathological study, the stomachs were dissected out, washed with cold water and kept in $10 \%$ neutral formalin saline. The sections ( $5 \mu \mathrm{m}$ thickness) were cut into glass slides and stained with hematoxylin and eosin (H\&E) (17). The glandular stomach in each animal was then assessed microscopically as previously described by Li et al (18).

\section{Immunohistochemistry}

For immunostaining, $5 \mu \mathrm{m}$ sections were mounted on adhesive slides, deparaffinized and rehydrated. The sections were then subjected to heat induced epitope retrieval step in microwave for 15- 20 minutes. Afterward, tissue sections were incubated with 1: 200 diluted primary antibodies (Mouse monoclonal Anti-Bax and Anti-BCl2, Santa Cruz) for 12 hours at $4^{\circ} \mathrm{C}$ in humid chamber. After washing, the sections were then incubated with HRP labeled goat anti-mouse secondary antibody (Abcam, Cambridge, UK) for 2 hours followed by detection step using DAB Substrate kit (Thermo Scientific, IL, USA). Control negative slides were obtained by deletion of the primary antibody. Positive expression was quantified as area percent using Cell Sens dimensions (Olympus software).

\section{Statistical analysis}

One-way analysis of variance (ANOVA) followed by Tukey's multiple comparisons test using GraphPad Prism software, version 5 (Inc., San Diego, USA) was used at $P<$ 0.05 for significance of difference. Data were expressed as mean \pm standard error (SE).

\section{Results}

Yield of the mucilage and extraction

The yield was $2 \% \mathrm{w} / \mathrm{w}$. Monosaccharide composition is presented in Table 1. Glucose, fucose and N-acetyl glucosamine were the main monosaccharides, where galactomannan, glucomannan, or glucosamine polysaccharides were present in high amounts. With relatively lower amounts of glucuronic and galacturonic acids (Table 1).

Effects of MFA on ethanol-induced ulcer

Oral administration of absolute ethanol produced multiple mucosal lesions in the rat stomach. Where, the pre-treatment with Antodine, MFA, 100 and $200 \mathrm{mg} / \mathrm{kg}$ decreased the ethanol-induced gastric mucosal injuries (Figure 1) evidenced by a decrease in the ulcer index in rats $(3.1 \pm 0.12 ; 3.83 \pm 0.13$ and $3.5 \pm 0.19$, respectively), compared to that of the ethanol control group (6.27 \pm 0.34$)$ at $P<0.05$. Moreover, they also produced a significant
Table 1. Sugar composition expressed as g. $100 \mathrm{~g}^{-1}$ of carbohydrates present in the mucilage

\begin{tabular}{lcc}
\hline Name & Amount (g/100 g) & Retention time (min) \\
\hline Galacturonic acid & 13.39 & 6.283 \\
N-acetyl O- glucosamine & 39.88 & 7.286 \\
Glucuronic acid & 0.884 & 9.383 \\
D-Glucose & 13.45 & 11.124 \\
D-Fucose & 15.25 & 13.896 \\
\hline
\end{tabular}

Total amounts of monosaccharaides identified $=68.58$ Total amounts of organic acids identified $=14.27$

increase in the percentage of the ulcer protection by $50.1 \%, 38.58 \%$ and $43.73 \%$, respectively, for Antodine, MFA 100 and MFA $200 \mathrm{mg} / \mathrm{kg}$ treated groups, compared to ethanol control (Table 2).

Effects of MFA on oxidative stress biomarkers and inflammatory biomarkers

A reduction in stomach content of GSH and an elevation in stomach content of MDA were observed in ethanol group by $38 \%$ and $40 \%$, respectively, compared to normal data. Although, treatment with MFA 100 and $200 \mathrm{mg} /$ $\mathrm{kg}$ increased stomach content of GSH by $13 \%$ and $16 \%$, respectively and decreased stomach content of MDA by $16 \%$ and $19 \%$, respectively, as compared to ulcer group (Figure 2).

Administration of ethanol produced an elevation in stomach contents of TNF- $\alpha$, IL- 6 and MPO by 1.2 fold, 27 fold and 2.7 fold, respectively, as compared to normal control values, where administration of MFA at 100 and $200 \mathrm{mg} / \mathrm{kg}$ reduced stomach contents of TNF- $\alpha$ by $41 \%$ and $39 \%$; IL- 6 by $22 \%$ and $33 \%$ and MPO by $24 \%$ and $29 \%$, respectively, as compared to ulcer group (Figure 3).

Effect of MFA on cytoprotective and cell proliferative markers

Ethanol injection led to an inhibition of PGE2 secretion, while it reversed by MFA, $200 \mathrm{mg} / \mathrm{kg}$ to the normal levels. It elevated PGE2 by $29 \%$ as compared to reference drug Antodine (Figure 4).

Ethanol administration produced a reduction in stomach contents of HSP-70 and VEGF by $87 \%$ and $71 \%$, respectively, as compared to normal group. Treatment with MFA, $200 \mathrm{mg} / \mathrm{kg}$ increased the stomach contents of HSP-70 by 4 folds, and VEGF by 2.2 folds compared to ethanol group. In addition, MFA had a higher potency than Antodine in elevating HSP-70 by $31 \%$ (Figure 4 ).

Histopathological examination

Microscopic examination of the glandular stomach of rats from normal group revealed the normal structure of glandular mucosa with its normal simple columnar epithelial cover and gastric glands containing chief and parietal cells (Figure 5a and 5b). Exposure to ethanol 


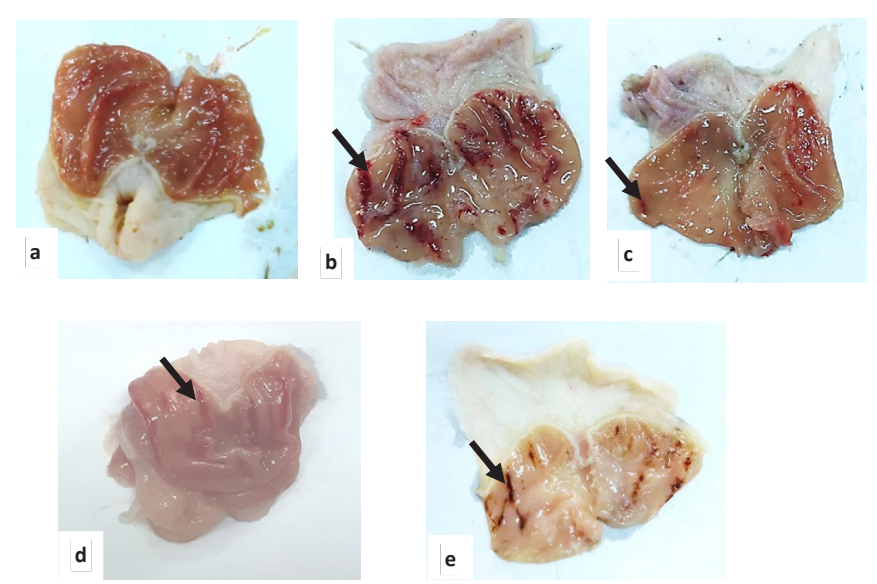

Figure 1. Gross appearance of gastric mucosa from rats; (a) Normal group, (b) Ethanol (5 mL/kg) group showed sever gastric mucosal injuries (arrow), (c) Ethanol+ Antodine $(20 \mathrm{mg} / \mathrm{kg}$ ) group showed mild gastric mucosal injuries (arrow), (d) Ethanol+ MFA (100 mg/kg) group showed moderate gastric mucosal injuries (arrow), and (e) Ethanol+ MFA (200 mg/kg) group showed moderate gastric mucosal injuries (arrow). MFA; mucilage fraction of Argel.

Table 2. Effect of mucilage fraction of Argel $(100 \mathrm{mg} / \mathrm{kg}$ and $200 \mathrm{mg} / \mathrm{kg})$ on ethanol-induced ulcer

\begin{tabular}{lcc}
\hline Groups & Ulcer index (mean \pm SE) & \% Ulcer protection \\
\hline i- Normal & $0 \pm 00$ & $100 \%$ \\
ii- Ethanol & $6.27 \pm .33^{\mathrm{a}}$ & - \\
iii- Ethanol+Antodine, $20 \mathrm{mg} / \mathrm{kg}$ b.wt & $3.1 \pm 0.11^{\mathrm{ab}}$ & $50.1 \%$ \\
iv- Ethanol+MFA, $100 \mathrm{mg} / \mathrm{kg}$ b.wt & $3.83 \pm 0.13^{\mathrm{ab}}$ & $38.5 \%$ \\
v- Ethanol+MFA, $200 \mathrm{mg} / \mathrm{kg}$ b.wt & $3.5 \pm 0.19^{\mathrm{ab}}$ & $43.7 \%$ \\
\hline
\end{tabular}

MFA: mucilage fraction of Argel.

All the values are presented as means \pm standard error of the means (SE) and $n=8$. Statistical analysis was carried out by one-way ANOVA followed by HSD Tukey's multiple comparisons test.

a Significantly different from normal control at $P<0.05$.

${ }^{\mathrm{b}}$ Significantly different from ethanol at $P<0.05$.

resulted in serious histological alterations represented by extensive mucosal damage, desquamation of Lamina epithelialis, necrosis in gastric glands, diffuse periglandular hemorrhage and mononuclear inflammatory cells infiltrations (Figure 5c-5e). Administration of Antodine exerted some protection against ethanol induced gastric damage (Figure $5 \mathrm{f}$ and $5 \mathrm{~g}$ ). Administration of MFA,
$(100 \mathrm{mg} / \mathrm{kg})$ resulted only in mild protective action; some epithelial losses were observed with focal hemorrhagic damage within the gastric mucosa (Figure 5h-5j). The higher dose of MFA exerted the best protective action against ethanol induced gastric damage, the glandular mucosa appeared apparently normal (Figure 5k) and the intact epithelial surface appeared covered by healthy
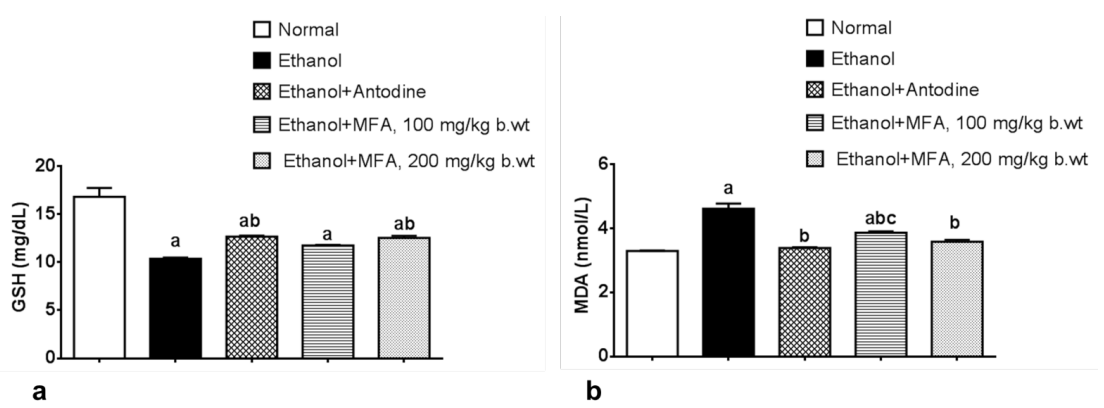

Figure 2. Effect of MFA on oxidative stress biomarkers in ethanol-induced ulcer as compared to Antodine (20 mg/kg); (a) GSH (mg/dL), (b) MDA (nmol/L). All the values are presented as means \pm standard error of the means (SE) and $n=8$. GSH; glutathione, MDA; malondialdehyde, MFA, mucilage fraction of

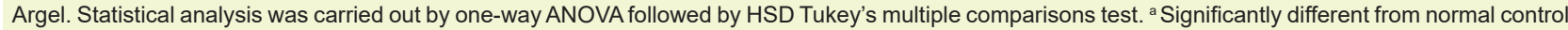

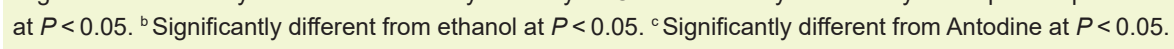




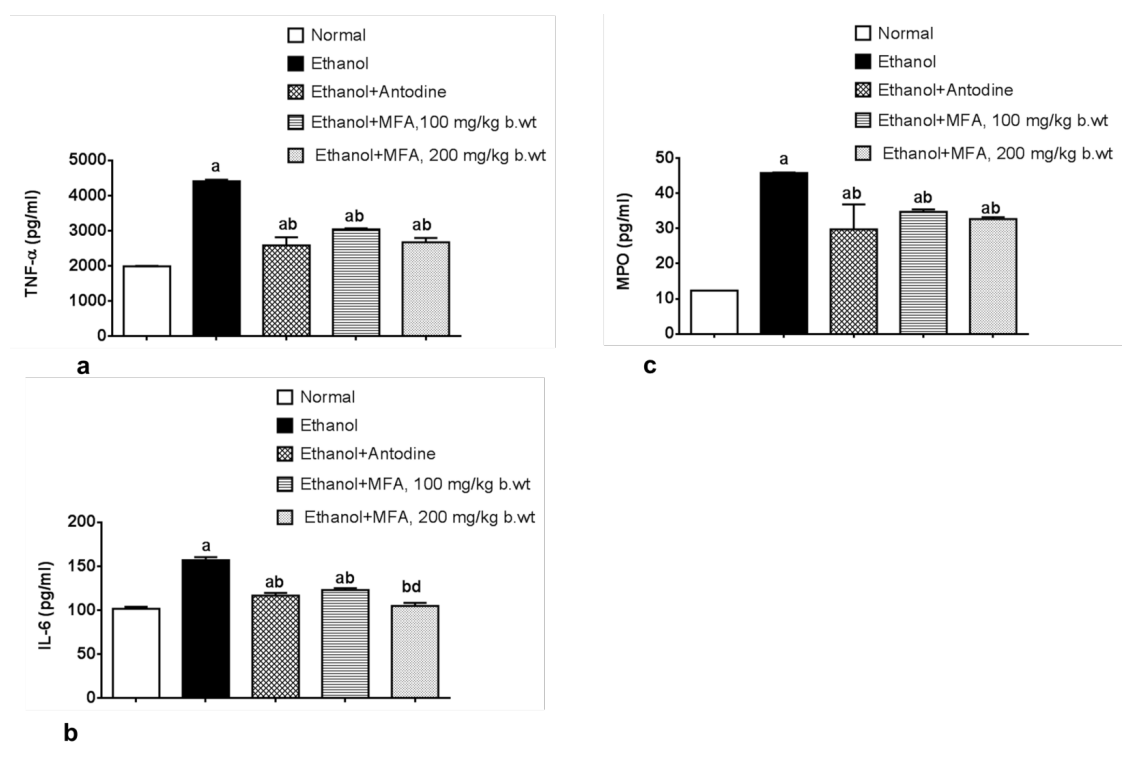

Figure 3. Effect of MFA on inflammatory cytokines in ethanol-induced ulcer as compared to Antodine (20 mg/kg); (a) TNF- $\alpha$ (pg/mL), (b) IL-6 (pg/mL), c) MPO $(\mathrm{pg} / \mathrm{mL})$. All the values are presented as means \pm standard error of the means (SE) and $n=8$. IL-6; interleukin-6, TNF- $\alpha$; tumor necrosis factor-alpha, MFA; mucilage fraction of Argel, MPO, myeloperoxidase.

Statistical analysis was carried out by one-way ANOVA followed by HSD Tukey's multiple comparisons test. a Significantly different from normal control at $P<0.05$. ${ }^{b}$ Significantly different from ethanol at $P<0.05$. ${ }^{\circ}$ Significantly different from Antodine at $P<0.05$.
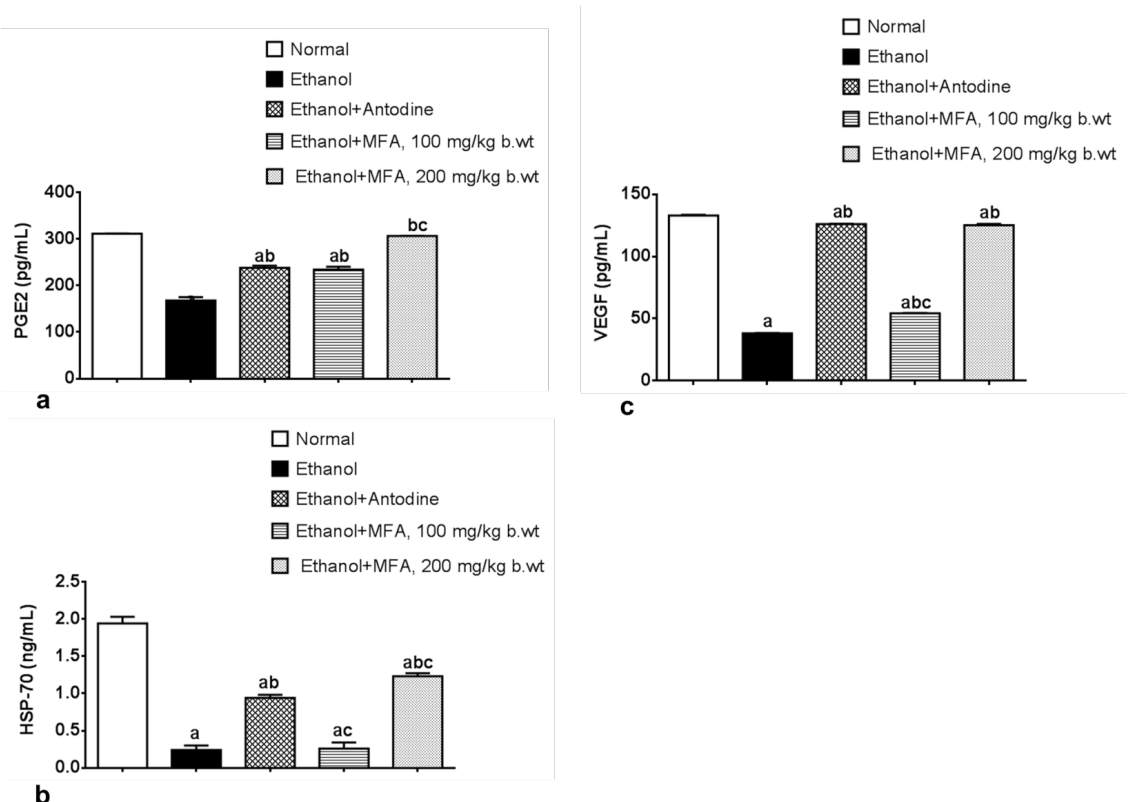

Figure 4. Effect of MFA on gastric ulcer healing biomarkers in ethanol-induced ulcer as compared to Antodine (20 mg/kg); (a) PGE2 (pg/mL), (b) HSP-70 $(\mathrm{ng} / \mathrm{mL})$ \& (c) VEGF $(\mathrm{pg} / \mathrm{mL})$. All the values are presented as means \pm standard error of the means (SE) and $\mathrm{n}=8$. HSP-70; Heat shock protein-70, MFA; mucilage fraction of Argel, PGE2; prostaglandin E2, VEGF; vascular endothelial growth factor.

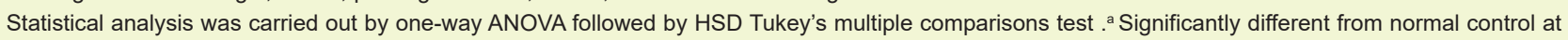
$P<0.05$. ' Significantly different from ethanol at $P<0.05$.

mucus cover (Figure 51). The only remarkable finding was the congestion at the deep mucosa with mild perivascular oedema at the submucosa (Figure $5 \mathrm{~m}$ ).

Histological scoring of the lesions encountered in the glandular stomach is summarized in Figure 6; generally, the group received ethanol exhibited significant increase $(P<0.05)$ in all of the estimated parameters compared to the other groups. Administration of MFA, $(200 \mathrm{mg} /$ $\mathrm{kg})$ resulted in the highest significant decrease $(P<0.05)$ in the total histological score compared with the ethanol 


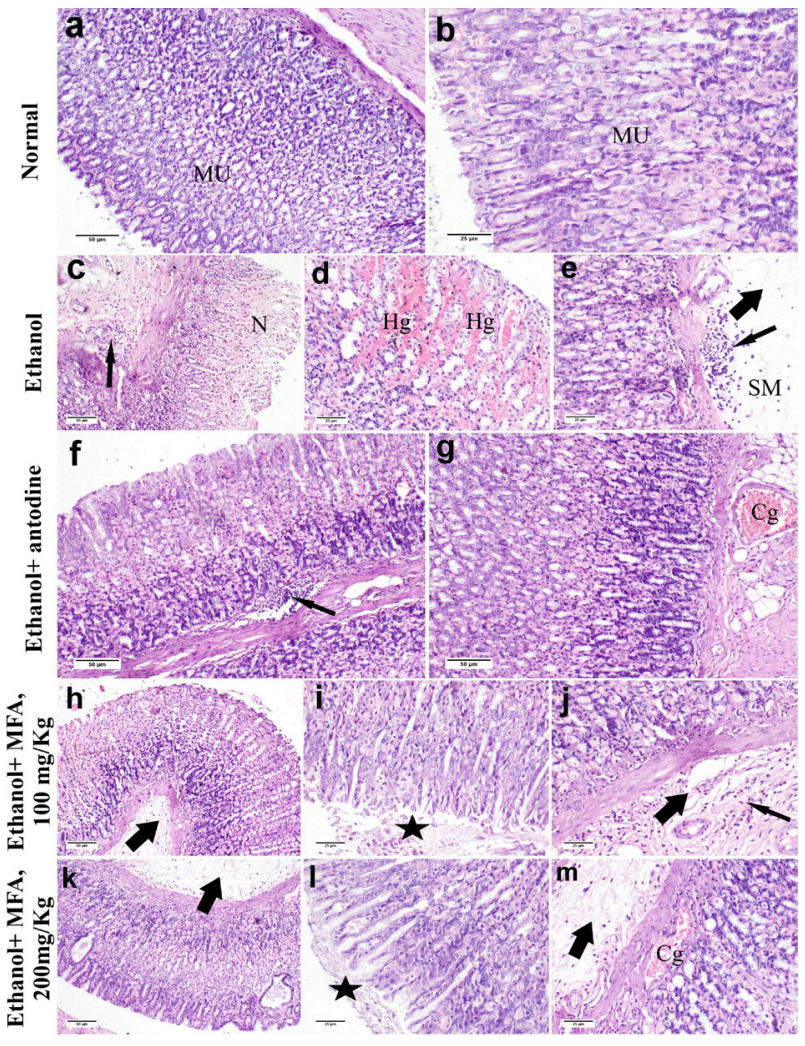

Figure 5. Photomicrograph of glandular stomach of rat (H\&E), (a, b) Normal group, (c-e) Ethanol group, (f, g) Ethanol+ Antodine group, (hj) Ethanol+ MFA, 100mg/kg group, (k-m) Ethanol+ MFA, $200 \mathrm{mg} / \mathrm{kg}$ group. MFA; mucilage fraction of Argel. MU: mucosa, N: necrosis and hemorrhagic damage, Hg: hemorrhage, SM: submucosa, thin arrows: inflammatory cells, Cg: congestion, Stars: mucus and thick arrows: edema.

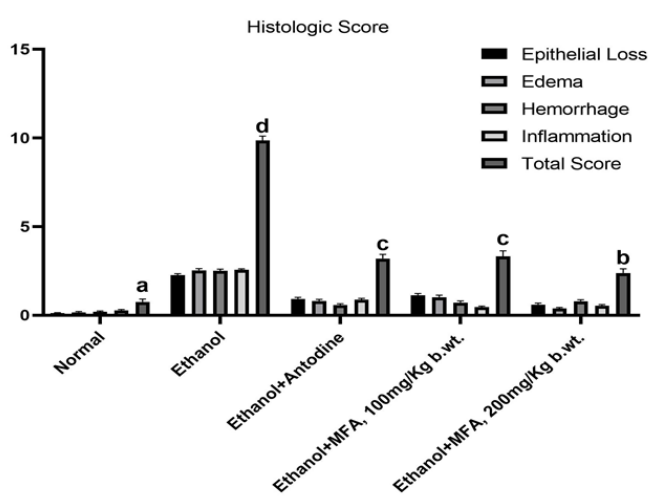

Figure 6. Histological score of the different groups in ethanol-induced gastric ulcer in male rats $(n=8)$. Data are expressed as means $\pm S E$. a, $b, c$ and $d$ indicate significant difference within the same data series at $P<0.05$. MFA; mucilage fraction of Argel.

group. The effect of MFA, $(100 \mathrm{mg} / \mathrm{kg})$ showed significant $(P<0.05)$ protective action which was similar to Antodine.

Immunohistochemistry of $\mathrm{Bax}$ and $\mathrm{BCl} 2$

The immunostaining of Bax and quantification as area percentage is illustrated in Figure 7. Compared to the normal control group, ethanol administration caused significant triggering $(P<0.05)$ in Bax expression within the glandular stomach. No significant difference $(P<0.05)$ was detected between group III and IV, while the administration of MFA (200 mg/kg), showed the highest reduction $(P<0.05)$ in Bax expression compared to the ethanol group.

Figure 8 shows the immune expression of $\mathrm{BCl} 2$ with the highest value recorded in the normal control group comparing to the other groups. Ethanol caused a significant reduction $(P<0.05)$ of $\mathrm{BCl} 2$ positive cells within the glandular stomach compared to the normal control group. Among the tested agents, both doses of MFA succeeded to keep significantly higher $(P<0.05)$ values of $\mathrm{BCl} 2$ within the stomach.

\section{Discussion}

Mucilage as a chemical class of polysaccharide could be used for several therapeutic purposes through oral or topical forms (3). The mucilage fraction isolated from $S$. argel was investigated for its ulcer healing potential as hope to replace the synthetic drugs having a lot of side effects and poor healing properties.

A lot of studies have reported that alcohol causes severe gastric mucosal injury and it is commonly used model to assess the gastroprotective effect of new medications and herbal products (19). The results of our study demonstrated that the intragastric administration of absolute ethanol caused multiple gastric mucosal lesions by gross examination along with a significant increase $(P<0.05)$ in gastric UI in ethanol group II compared to normal rats (group I). The administration of MFA successively ameliorated these lesions and increased the ulcer protection percentages by $38.5 \%$ and $43.7 \%$, respectively, at doses of 100 and $200 \mathrm{mg} / \mathrm{kg}$. Likewise, these data were in agreement with the histopathological study of gastric mucosa, as ethanol-administered group showed several mucosal histological derangements including submucosal edema, congested blood vessels, necrosis and loss of epithelial cells and marked infiltration with inflammatory cells. While MFA pretreatment showed gastric mucosa as normal rats where all lesions were healed.

Oxidative stress has been well related to the pathological progression of gastric ulcer, leading to gastric mucosal injury with cell apoptosis in late stages $(20,21)$. Our results showed also that ethanol as an aggressive factor, caused a significant oxidative stress-related damage leading to increase $(P<0.05)$ in oxidative stress biomarkers and inflammatory cytokines compared to the normal control group. The ulcer induced group showed also a significant increase in MDA level in stomach tissue and decrease in reduced GSH level. Where, the pretreatment with MFA $(100 \mathrm{mg} / \mathrm{kg}$ ) decreased significantly the level of MDA 


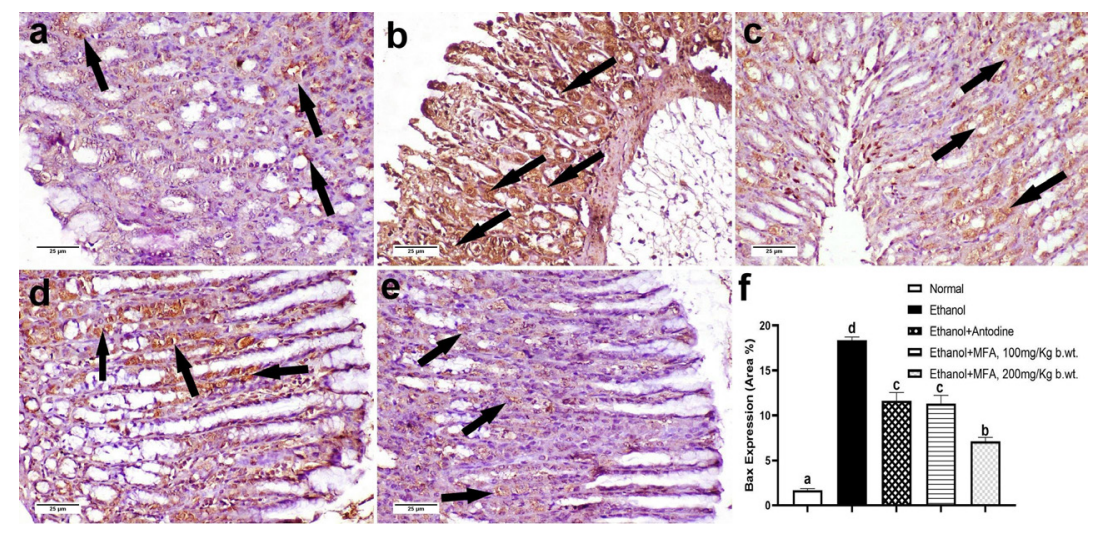

Figure 7. Bax expression (arrows), in glandular stomach of rat (Immunostaining) (a) Normal group, (b) Ethanol group, (c) Ethanol+ Antodine group, (d) Ethanol + MFA, (100 mg/ kg b.wt), (e) Ethanol+ MFA, $(200 \mathrm{mg} / \mathrm{kg}$ b.wt) and (f) Expression of Bax as area percentage, data was presented as means \pm SE. $\mathrm{a}, \mathrm{b}, \mathrm{c}$ and $\mathrm{d}$ indicate significant difference at $P<0.05$.

Bax; B-cell lymphoma protein 2 (BCl2)-associated X, MFA; mucilage fraction of Argel.

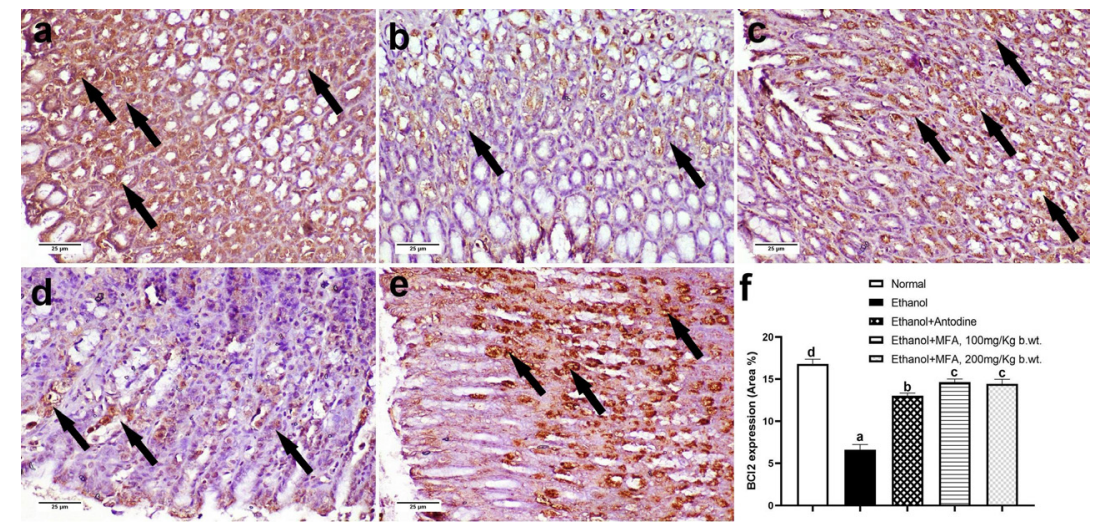

Figure 8. BCl2 expression (arrows), in glandular stomach of rat (Immunostaining) (a) Normal group, (b) Ethanol group, (c) Ethanol+ Antodine group, (d) Ethanol+ MFA, (100 mg/ kg), (e) Ethanol+ MFA, (200 mg/ kg) and (f) Expression of $\mathrm{BCl} 2$ as area percentage, data was presented as means \pm SE. a, b, c, and $\mathrm{d}$ indicate significant difference at $P<0.05$.

$\mathrm{BCI}$; B-cell lymphoma protein 2, MFA; mucilage fraction of Argel.

only, while MFA (200 mg/kg) elevated the levels of GSH and returned MDA to its normal value. From these results we can conclude that the gastroprotective effect of MFA was, in part, due to its potent anti-oxidant activity.

There is a strong relationship between gastric ulcer damage and inflammation induced by ethanol (22). The inflammatory response after ethanol leads to initiation of macrophages to release pro-inflammatory mediators such as TNF- $\alpha$, IL- 6 , and MPO with the accumulation of neutrophils, resulting in destruction of the mucosal barrier (23). These cytokines in sequence cause the release of ROS (oxygen-derived free radicals), in that way assisting the occurrence of gastric ulcers. This, in turn, resulted in high levels of TNF- $\alpha$, IL-6, and MPO in the ethanol control group. In contrast, MFA pre-treatment reserved the elevation of these levels.

Prostaglandin E2 (PGE2) is a vital mediator in maintaining the integrity of gastric mucosal defence and gastric ulcer healing. It has an important role as a gastric mucus secretion regulator. PGE2 increases blood flow, mucus secretion and bicarbonate. It also sustains the cellular integrity in the mucosa $(24,25)$. Therefore, the decreased PGs levels are important events in the etiology of mucosal ulceration. Our results revealed that the gastroprotective effect of MFA might be partially associated with the stimulations of gastric PGs releases.

HSP-70 is another factor, which can protect stomach mucosa present in mammalian cells to protect the mitochondria from the different injurious factors and inhibit the stress-induced apoptosis process (26). Therefore, the overexpression of HSP-70 protects against the gastric mucosal damage and also repairs the damaged cells helping in ulcer healing of gastric mucosa (27). Ethanol-induced gastric ulcers inhibited the HSP70 release, where MFA $(200 \mathrm{mg} / \mathrm{kg})$ and Antodine significantly elevated its levels and further proved the cytoprotection of them.

VEGF is another factor with an important role in gastric 
ulcer healing through its effect on angiogenesis $(28,29)$. Furthermore, excess acid secretion reduces the process of ulcer healing via altering angiogenesis and decreasing VEGF in ethanol-induced gastric lesions (30). Our data indicated that MFA protected gastric mucosa against ethanol-induced gastric lesion via pro-angiogenic actions owing to upregulation of VEGF expression in gastric fibroblasts leading to ulcer repair.

We can conclude that the reduction of gastric ulcer may be contributed to the ability of MFA to enhance the PGE2 generation at ulcer margin which leads to stimulation of VEGF that activates migration and proliferation of cells at the edge of the ulcer and promotes the angiogenesis, formation of granulation tissue, and remodelling of connective tissues during the process of ulcer repair.

A lot of studies have reported that $\mathrm{Bax}$ and $\mathrm{BCl} 2$ are associated with apoptosis throughout mitochondrial impairment and have an important role in interruption of stomach mucosal integrity later to ethanol administration (30). Free radicals lead to activation of intrinsic pathway of apoptosis (Bax) in areas of ulcer resulting in cell apoptosis. Our study showed that MFA pre-treatment downregulated the immunohistochemical of Bax expression in the ulcer-induced group, and successfully inhibited the cell death of gastric mucosal cells, consequently provided an anti-apoptosis approach against gastric ulcer destruction. Finally, we can conclude that polysaccharides are very interesting therapy for treatment of a lot of diseases such as gastric ulcer.

\section{Conclusion}

The potential usage of MFA for ulcer healing was assessed in ethanol induced gastric ulcer, where MFA showed a promising activity through anti-oxidant, anti-inflammatory, proangiogenic, cytoprotective and antiapoptotic role. Thus, the usage of MFA is highly recommended therapy for gastric ulcer treatment.

\section{Authors' contributions}

RA conceived and designed the study. RA and AS conducted the experiment and collected the data. AS performed the analysis. AA performed the histopathological study. RA, AS and AA interpreted the data and wrote the paper. EA supervised and revised the paper. All read and confirmed the final version of manuscript for publication

\section{Conflict of interests}

All authors confirm that there is no conflict of interest to disclose.

\section{Ethical considerations}

This study protocol was approved by the ethics committee of the Institutional Research Ethics Committee at the Faculty of Pharmacy, Cairo University, Egypt. (Ethical code: MP-2575). The ethical issues (including plagiarism, misconduct, data fabrication, falsification, double publication or submission, redundancy) have been completely observed by the authors.

\section{Funding/Support}

This study received no funding or grant.

\section{References}

1. Cruz-Rubio JM, Loeppert R, Viernstein H, Praznik W. Trends in the use of plant non-starch polysaccharides within food, dietary supplements, and pharmaceuticals: beneficial effects on regulation and wellbeing of the intestinal tract. Sci Pharm. 2018;86(4):49. doi: 10.3390/scipharm86040049.

2. Soukoulis C, Gaiani C, Hoffmann L. Plant seed mucilage as emerging biopolymer in food industry applications. Curr Opin Food Sci. 2018;22:28-42. doi: 10.1016/j. cofs.2018.01.004.

3. Ameri A, Heydarirad G, Mahdavi Jafari J, Ghobadi A, Rezaeizadeh H, Choopani R. Medicinal plants contain mucilage used in traditional Persian medicine (TPM). Pharm Biol. 2015;53(4):615-23. doi: 10.3109/13880209.2014.928330.

4. Sharma DR, Sharma A, Kaundal A, Rai PK. Herbal gums and mucilage as excipients for Pharmaceutical Products. Res J Pharmacogn Phytochem. 2016;8(3):145-52. doi: 10.5958/0975-4385.2016.00026.1.

5. El-Shiekh RA, Al-Mahdy DA, Mouneir SM, Hifnawy MS, Abdel-Sattar EA. Anti-obesity effect of argel (Solenostemma argel) on obese rats fed a high fat diet. J Ethnopharmacol. 2019;238:111893. doi: 10.1016/j.jep.2019.111893.

6. Al-Wajeeh NS, Hajerezaie M, Noor SM, Halabi MF, AlHenhena N, Azizan AH, et al. The gastro protective effects of Cibotium barometz hair on ethanol-induced gastric ulcer in Sprague-Dawley rats. BMC Vet Res. 2017;13(1):27. doi: 10.1186/s12917-017-0949-z.

7. Park JU, Kang JH, Rahman MAA, Hussain A, Cho JS, Lee YI. Gastroprotective effects of plants extracts on gastric mucosal injury in experimental Sprague-Dawley rats. Biomed Res Int. 2019;2019:8759708. doi: 10.1155/2019/8759708.

8. Mousa AM, El-Sammad NM, Hassan SK, Madboli A, Hashim AN, Moustafa ES, et al. Antiulcerogenic effect of Cuphea ignea extract against ethanol-induced gastric ulcer in rats. BMC Complement Altern Med. 2019;19(1):345. doi: 10.1186/s12906-019-2760-9.

9. Brito SA, de Almeida CLF, de Santana TI, da Silva Oliveira AR, do Nascimento Figueiredo JCB, Souza IT, et al. Antiulcer activity and potential mechanism of action of the leaves of Spondias mombin L. Oxid Med Cell Longev. 2018;2018:1731459. doi: 10.1155/2018/1731459.

10. Kouitcheu Mabeku LB, Nanfack Nana B, Eyoum Bille B, Tchuenteu Tchuenguem R, Nguepi E. Anti-Helicobacter pylori and antiulcerogenic activity of Aframomum pruinosum seeds on indomethacin-induced gastric ulcer in rats. Pharm Biol. 2017;55(1):929-36. doi: 10.1080/1388020 9.2017.1285326.

11. Sharifi-Rad M, Fokou PVT, Sharopov F, Martorell M, Ademiluyi AO, Rajkovic J, et al. Antiulcer agents: from plant extracts to phytochemicals in healing promotion. Molecules. 2018;23(7). doi: 10.3390/molecules23071751. 
12. Radwan HM, Nazif NM, Abou-Setta LM. Phytochemical investigation of Salicornia fruticosa (L.) and their biological activity. Res J Med Med Sci. 2007;2(2):72-8.

13. Njintang NY, Boudjeko T, Tatsadjieu LN, Nguema-Ona E, Scher J, Mbofung CM. Compositional, spectroscopic and rheological analyses of mucilage isolated from taro (Colocasia esculenta L. Schott) corms. J Food Sci Technol. 2014;51(5):900-7. doi: 10.1007/s13197-011-0580-0.

14. Ode OJ, Asuzu OV. Investigation of Cassia singueana leaf extract for antiulcer effect using ethanol-induced gastric ulcer model in rat. International Journal of Plant, Animal and Environmental Sciences. 2011;1(1):1-7.

15. Sen S, Asokkumar K, Umamaheswari M, Sivashanmugam AT, Subhadradevi V. Antiulcerogenic effect of gallic acid in rats and its effect on oxidant and antioxidant parameters in stomach tissue. Indian J Pharm Sci. 2013;75(2):149-55.

16. Salama RAA, Abdelsalam RM, Abdel-Salam OME, Khattab MM, Salem NA, El-Khyat ZA, et al. Modulation of gastric acid secretion by cannabinoids in rats. J Biochem Mol Toxicol. 2019;33(3):e22256. doi: 10.1002/jbt.22256.

17. Bancroft JD. Histochemical Techniques. ButterworthHeinemann; 2013.

18. Li WF, Hao DJ, Fan T, Huang HM, Yao H, Niu XF. Protective effect of chelerythrine against ethanol-induced gastric ulcer in mice. Chem Biol Interact. 2014;208:18-27. doi: 10.1016/j. cbi.2013.11.011.

19. Escobedo-Hinojosa WI, Gomez-Chang E, García-Martínez K, Guerrero Alquicira R, Cardoso-Taketa A, Romero I. Gastroprotective mechanism and ulcer resolution effect of Cyrtocarpa procera methanolic extract on ethanol-induced gastric injury. Evid Based Complement Alternat Med. 2018;2018:2862706. doi: 10.1155/2018/2862706.

20. Aziz RS, Siddiqua A, Shahzad M, Shabbir A, Naseem N. Oxyresveratrol ameliorates ethanol-induced gastric ulcer via downregulation of IL-6, TNF- $\alpha$, NF-kB, and COX-2 levels, and upregulation of TFF-2 levels. Biomed Pharmacother. 2019;110:554-60. doi: 10.1016/j.biopha.2018.12.002.

21. Sistani Karampour N, Arzi A, Rezaie A, Pashmforoosh M, Kordi F. Gastroprotective Effect of zingerone on ethanol-induced gastric ulcers in rats. Medicina (Kaunas).
2019;55(3). doi: 10.3390/medicina55030064.

22. de Souza MC, Vieira AJ, Beserra FP, Pellizzon CH, Nóbrega RH, Rozza AL. Gastroprotective effect of limonene in rats: influence on oxidative stress, inflammation and gene expression. Phytomedicine. 2019;53:37-42. doi: 10.1016/j. phymed.2018.09.027.

23. Fahmy NM, Al-Sayed E, Michel HE, El-Shazly M, Singab ANB. Gastroprotective effects of Erythrina speciosa (Fabaceae) leaves cultivated in Egypt against ethanol-induced gastric ulcer in rats. J Ethnopharmacol. 2020;248:112297. doi: 10.1016/j.jep.2019.112297.

24. Takeuchi K, Amagase K. Roles of prostaglandin E and EP receptors in mucosal protection and ulcer healing in the gastrointestinal tract. Arch Dig Disord. 2017;1(2):1-16.

25. Tsuge K, Inazumi T, Shimamoto A, Sugimoto Y. Molecular mechanisms underlying prostaglandin E2-exacerbated inflammation and immune diseases. Int Immunol. 2019;31(9):597-606. doi: 10.1093/intimm/dxz021.

26. Kiang JG, Tsokos GC. Heat shock protein $70 \mathrm{kDa}$ : molecular biology, biochemistry, and physiology. Pharmacol Ther. 1998;80(2):183-201. doi: 10.1016/s0163-7258(98)00028-x.

27. Rokutan K. Role of heat shock proteins in gastric mucosal protection. J Gastroenterol Hepatol. 2000;15 Suppl:D12-9. doi: $10.1046 / j .1440-1746.2000 .02144 . x$.

28. Suzuki N, Takahashi S, Okabe S. Relationship between vascular endothelial growth factor and angiogenesis in spontaneous and indomethacin-delayed healing of acetic acid-induced gastric ulcers in rats. J Physiol Pharmacol. 1998;49(4):515-27.

29. Tarnawski AS, Ahluwalia A, Jones MK. Angiogenesis in gastric mucosa: an important component of gastric erosion and ulcer healing and its impairment in aging. J Gastroenterol Hepatol. 2014;29 Suppl 4:112-23. doi: 10.1111/jgh.12734.

30. Zhou D, Yang Q, Tian T, Chang Y, Li Y, Duan LR, et al. Gastroprotective effect of gallic acid against ethanolinduced gastric ulcer in rats: involvement of the $\mathrm{Nrf2} / \mathrm{HO}-1$ signaling and anti-apoptosis role. Biomed Pharmacother. 2020;126:110075. doi: 10.1016/j.biopha.2020.110075. 